\title{
Modelling of PLA melt rheology and batch mixing energy balance
}

\author{
Pierre Erwan Le Marec ${ }^{\mathrm{a}, \mathrm{b}}$, Jean-Christophe Quantin ${ }^{\mathrm{a}, *}$, Laurent Ferry ${ }^{\mathrm{a}}$, Jean-Charles Bénézet ${ }^{\mathrm{a}}$, \\ Stéphane Guilbert ${ }^{\mathrm{b}}$, Anne Bergeret ${ }^{\mathrm{a}}$
}

${ }^{a}$ Ecole des mines d'Alès, Centre des Matériaux des Mines d'Alès (C2MA), 6 avenue de Clavières, 30319 Alès Cedex, France

${ }^{\mathrm{b}}$ UMR 1208 Ingénierie des Agropolymères et Technologies Emergentes (IATE), INRA/Agro.M/UM2/CIRAD, Campus de la Gaillarde, 2 place Pierre Viala,

34060 Montpellier Cedex 01, France

\section{A B S T R A C T}

A method to determine the overall energy balance of neat PLA processing in a batch mixer was proposed. Energy consumption calculations rely upon shear rate and viscosity calculations using a double-Couette approximation. In the case of PLA mixing, it was found that the energy consumption is increased with an increasing rotor speed and decreased with an increasing temperature. During the melting phase the energy consumption is not strongly affected by the process parameters and the energy efficiency is close to 1 . During the mixing phase, for a given viscosity, the energy efficiency is increased with increasing rotor speed or temperature and a method to optimise the process parameters to obtain a low viscosity with limited degradation and high energy efficiency was proposed. Moreover a comparison is given between the double-Couette approximation and conventional rheometry (rotational and capillary). Conventional rheometry translates into an overestimation of the viscosity especially at low temperature. This overestimation could probably be explained by the high sensitivity of rheology to molar mass reduction.

Keywords:

Polylactide

Batch mixer

Energy efficiency

Rheology

\section{Introduction}

Polymer and composite industry is faced to many issues since sustainable development entered the mainstream. New environmentally-friendly ways to think and to design call for the introduction of new polymers and composites with an enhanced sustainability. Several roads were investigated to improve the sustainability of such materials. First, renewable raw materials are now widely used to develop new polymers and composites [16,3], the input of bio-based raw materials usually lowers their environmental impact [5,2]. Second, biodegradable (or compostable) polymers are of great interest since they permit to

\footnotetext{
* Corresponding author. Tel.: +33 4667853 46; fax: +33 466785365 . E-mail address: jean-christophe.quantin@mines-ales.fr (J.-C. Quantin).
}

manage the end-of-life in an eco-friendly way [33]. Finally, the reduction of energy consumption and pollutant emissions that occurs through the successive transformation processes of the life cycle is required to further improve the environmental efficiency [29,35].

Poly(lactic acid) (PLA) is both bio-based (ring opening polymerisation of lactic acid obtained from starch fermentation) and compostable (hydrolysis of the ester double bond in presence of moisture) $[1,17,26,25,36]$. Since high molar mass PLA polymers are available in large amount, they have been considered as promising materials to fulfil the sustainability requirements.

PLA is usually processed in a molten state under shear and elongational conditions (extrusion, injection...) which require understanding its thermal and rheological behaviour to optimise the process parameters [25]. Moreover, its thermal stability above the melting point remains 
rather low and the ester linkages of PLA tend to degrade during melt processing [42] which strongly affects the rheological behaviour. The final properties, e.g. mechanical properties, thermal stability and biodegradation rate, are then affected by the processing conditions $[22,37,19$, $18,6]$. The degradation occurring during processing under shear conditions was studied in a previous work [23] and modelled using a statistical model according to Wachsen et al. [39]. The influence of time on the molar mass evolution was modelled using a two-parameter model based on reactions schemes describing both degradation and recombination processes (Eqs. (1) and (2)) [42,39]:

$P_{i} \rightarrow P_{i-j}+P_{j}$

$P_{i-j}+P_{j} \rightarrow P_{i}$

where $P_{i}$ is a PLA polymer chain with a degree $\mathrm{i}$ of polymerisation. Using two statistic rate constants $k_{d}$ and $k_{c}$ respectively for degradation reactions and recombination reactions, the evolution of the concentration of each species $P_{i}$ can be described by the following differential equation system (Eq. (3)):

$$
\begin{aligned}
\frac{d\left[P_{i}\right]}{d t}= & -k_{d}(i-1)\left[P_{i}\right]+2 k_{d} \sum_{j=i+1}^{\infty}\left[P_{j}\right]+\frac{1}{2} k_{c} \sum_{j=1}^{i-1}\left[P_{j}\right]\left[P_{i-j}\right] \\
& -k_{c}\left[P_{i}\right] \sum_{j=1}^{\infty}\left[P_{j}\right]
\end{aligned}
$$

The first term of Eq. (3) describes the $(i-1)$ possibilities of splitting of a molecule $P_{i}$. The second term describes every possible formation of this molecule by degradation of the molecules with a chain length $j$ greater than $i$. The third term represents every possible formation of this molecule by recombination of two molecules with chain lengths $j$ and $(i-j)$ lower than $i$. The last term describes every possible disappearance of this molecule due to its recombination with other species.

The influence of temperature on both constants was modelled with an Arrhenius law (Eqs. (4) and (5)).

$k_{d}=A_{d} \exp \left[-\frac{E_{a_{d}}}{R T}\right]$

$k_{c}=A_{c} \exp \left[-\frac{E_{a_{c}}}{R T}\right]$

where $A_{d}$ and $A_{c}$ are respectively the degradation and recombination rate constants at the reference temperature, $E_{a_{d}}$ and $E_{a_{c}}$ are the respective activation energies for the degradation and recombination processes, $R$ is the gas constant $\left(8.314 \mathrm{~J} \mathrm{~mol}^{-1} \mathrm{~K}^{-1}\right)$, and $T$ is the polymer temperature (K).

Degradation and recombination rate constants were determined to model the effect of mixing time, as well as activation energies to take into account the influence of temperature. Table 1 presents the values of rate constants and activation energies for both degradation and recombination processes (commercial grade of PLA Ingeo ${ }^{\mathrm{TM}} 7000 \mathrm{D}$ from NatureWorks ${ }^{\circledR}$ LLC).

The aim of this article is to model the evolution of viscosity during processing taking into account the degradation that occurs and to observe the influence of process parameters on melt viscosity, energy balance and
Table 1

Degradation and recombination rate constants at reference temperature $\left(k_{d, r e f}\right.$ and $\left.k_{c, r e f}\right)$ and activation energies $\left(E_{a d}\right.$ and $\left.E_{a c}\right)$ for PLA at $T_{\text {ref }}=170{ }^{\circ} \mathrm{C}$ [23].

\begin{tabular}{llll}
\hline$E_{a d}\left(\mathrm{~kJ} \mathrm{~mol}^{-1}\right)$ & $k_{d, r e f}\left(10^{-6} \mathrm{~s}^{-1}\right)$ & $E_{a c}\left(\mathrm{~kJ} \mathrm{~mol}^{-1}\right)$ & $k_{c, r e f}\left(\mathrm{~L} \mathrm{~mol}^{-1} \mathrm{~s}^{-1}\right)$ \\
\hline 87.2 & 0.085 & 37.7 & 4.36 \\
\hline
\end{tabular}

efficiency. This work constitutes a first step in the analysis of energy balance dealing with batch mixing or extrusion compounding of PLA composites (especially cellulose fibres PLA composites). In this step the priority is given to batch mixing because, unlike extrusion compounding, the different phases (solid conveying, melting, melt mixing) are uncoupled. So each phase can be studied independently of each other.

\section{Theoretical considerations}

\subsection{Energy aspects}

Inside a twin-screw extruder which is the most widely used compounding machine in plastic industry, the screws bring mechanical energy which is a function of torque and screw speed (Eq. (6)) [32]. The thermally regulated barrel allows transferring thermal energy from the barrel to the polymer if the polymer temperature is lower than the barrel, or in the opposite case, from the polymer to the barrel (Eq. (7)) [38].

$\mathrm{SME}=\frac{\omega}{m} \int_{0}^{t \max } \Gamma(t) d t$

where SME is the specific mechanical energy $\left(\mathrm{J} \mathrm{kg}^{-1}\right), \omega$ is the screw speed $\left(\mathrm{rad} \mathrm{s}^{-1}\right), m$ is the weight of the extrudate $(\mathrm{kg}), t_{\max }$ is the time of extrusion (s) and $\Gamma(t)$ is the torque applied on the screws $(\mathrm{N} \mathrm{m})$.

$\mathrm{STE}=\frac{1}{m} \int_{0}^{t \max } \sum_{i}\left[h_{B_{i}}\left(T_{B_{i}}-\overline{T_{i}}\right) S_{B_{i}}+h_{S_{i}}\left(T_{S_{i}}-\overline{T_{i}}\right) S_{S_{i}}\right] d t$

where STE is the specific thermal energy $\left(\mathrm{J} \mathrm{kg}^{-1}\right)$ assuming a purely convective exchange between barrel and polymer, $i$ stands for each heating zone, $h_{B}$ (resp. $h_{S}$ ) is the convective heat transfer coefficient between the barrel (resp. screws) and the polymer $\left(\mathrm{W} \mathrm{m}^{-2} \mathrm{~K}^{-1}\right), T_{B_{i}}$ (resp. $T_{S_{i}}$ ) is the barrel (resp. screws) regulation temperature on zone $i\left({ }^{\circ} \mathrm{C}\right), \bar{T}_{i}$ is the average polymer temperature on zone $i$ $\left({ }^{\circ} \mathrm{C}\right)$ and $S_{B_{i}}$ (resp. $S_{S_{i}}$ ) is the contact area between the polymer and the barrel (resp. screws) wall $\left(\mathrm{m}^{2}\right)$.

However, extrusion is a continuous process in which several phenomena occur at the same time and are very difficult to uncouple. Indeed, when moving forward along the screws, pellets first melt and fillers are incorporated inside the molten matrix. So as to study separately the melting phase and the mixing phase, one possibility is to use a batch mixer.

During the melting phase in a batch mixer, a torque peak is observed as well as a strong increase of the material temperature and of the pressure inside the mixing chamber. It highlights strong plastic energy dissipation (PED) and frictional energy dissipation (FED) into heat due to 
contacts between granulates and also between granulates and the wall. According to Qian and Gogos [31], the energy balance on a volume $\mathrm{V}$ with a two-dimensional boundary $\mathrm{S}$ during the melting phase is given by Eq. (8):

$$
\begin{aligned}
\int_{V} \rho_{P} C_{p_{P}} \frac{d T}{d t} d V= & \int_{S} \nabla \cdot(k \nabla T) d S+\int_{V_{\text {melt }}} K \dot{\bar{\gamma}}^{n+1} d V_{\text {melt }} \\
& +\int_{V_{\text {solid }}} P E D d V_{\text {solid }}+\int_{V_{\text {solid }}} F E D d V_{\text {solid }} \\
& +\int_{V} \dot{S} d V
\end{aligned}
$$

where $\rho_{P}$ is the density of the polymer, $C_{p_{P}}$ is the heat capacity of the polymer, $d T / d t$ is the particle derivative of the temperature $\left(\frac{d T}{d t}=\frac{\partial T}{\partial t}+\vec{v} \cdot \nabla T\right), \vec{v}$ is the velocity vector, $k$ is the thermal conductivity of the polymer, $K$ and $n$ are respectively the consistency and the power law index of the polymer which is described with an incompressible power law $\left(\eta=K \dot{\bar{\gamma}}^{n-1}\right), \dot{\bar{\gamma}}$ is the generalised shear rate and $\dot{S}$ represents the other heat sources (such as chemical reactions or phase transitions). The left-hand term corresponds to the material internal energy change, the first term of the right-hand side is the conductive heat transfer through the boundary of the volume element, the second term is the viscous dissipation in the molten phase, and, the last term corresponds to the energy given or consumed by the possible chemical reactions and phase transitions.

For a thermoplastic semi-crystalline polymer, the efficiency of the melting phase is defined as the ratio between the theoretical energy consumed by the polymer to reach the set mixing temperature and the total specific energy delivered to the system (Eq. (9)):

$\eta_{\text {melt }}=\frac{\int_{T_{a m b}}^{T_{c}} C_{p_{P}}\left(T_{P}\right) d T_{P}+\Delta H_{m}}{\mathrm{SME}+\mathrm{STE}}$

where $T_{c}$ is the set mixing temperature $\left({ }^{\circ} \mathrm{C}\right), T_{a m b}$ is the ambient temperature $\left({ }^{\circ} \mathrm{C}\right), T_{P}$ is the polymer temperature $\left({ }^{\circ} \mathrm{C}\right)$ and $\Delta H_{m}$ is the melting enthalpy of the polymer $\left(\mathrm{J} \mathrm{kg}^{-1}\right)$.

Once the melting phase is over, the torque and temperature reach a plateau and the pressure drops off; this is the beginning of the mixing phase. The temperature of the polymer is higher than the barrel temperature because of the viscous dissipation. When the temperature reaches the plateau, the steady-state is reached and thus the conductive heat transfer from the polymer to the barrel is compensated by the viscous dissipation. In order to write this power balance, convective heat transfer is assumed between the molten polymer and the rotors because the latter are not thermally regulated. Three different hypotheses could be made:

- The rotors are at the polymer temperature $T_{p}$; there is no exchange between the rotors and the polymer.

- The rotors are at the barrel temperature; it is possible to assume an equivalent thermal transfer coefficient for both rotors and barrel.

- The rotors temperature varies during the mixing phase between initial and final temperatures and these temperatures should be measured.
Eqs. (10)-(12) are respectively simplified forms of Eq. (8) (the whole domain is supposed to be occupied by molten polymer so the terms FED and PED from Eq. (8) disappear) according to those hypotheses and considering a purely convective heat transfer (instead of conductive heat transfer) between the mixing chamber and rotors with the polymer:

$$
\begin{aligned}
& \int_{V_{\text {melt }}} \rho_{P} C_{p_{P}} \frac{d T_{P}}{d t} d V-\int_{V_{\text {melt }}} K \dot{\bar{\gamma}}^{n+1} d V_{\text {melt }}=h_{C}\left(T_{C}-T_{P}\right) S_{C} \\
& \int_{V_{\text {melt }}} \rho_{P} C_{p_{P}} \frac{d T_{P}}{d t} d V-\int_{V_{\text {melt }}} K \dot{\bar{\gamma}}^{n+1} d V_{\text {melt }}=h_{C+R}\left(T_{C+R}-T_{P}\right) S_{C+R} \\
& \int_{V_{\text {melt }}} \rho_{P} C_{p_{P}} \frac{d T_{P}}{d t} d V+\int_{V_{\text {rotor }}} \rho_{R} C_{p_{R}} \frac{d T_{R}}{d t} d V \\
& -\int_{V_{\text {melt }}} K \dot{\bar{\gamma}}^{n+1} d V_{\text {melt }}=h_{C}\left(T_{C}-T_{P}\right) S_{C}
\end{aligned}
$$

where $h_{C+R}, T_{C+R}$ et $S_{C+R}$ are respectively the equivalent convective heat transfer coefficient, the barrel temperature and the total surface of the mixing chamber and the rotors and $C_{p_{R}}$ is the heat capacity of the rotors.

In order to determine the heat transfer coefficient between the polymer and the mixing chamber and to deduce the specific thermal energy, it is then necessary to determine the viscosity of the polymer. Bousmina et al. [4] proposed a method to determine the viscosity in steady state (once melting is complete) from the measurement of the torque applied on the rotors in a batch mixer using a double-Couette approximation (Fig. 1). This method considers a steady laminar isothermal shear flow for an incompressible power-law fluid with a perfect adherence on the chamber walls and the rotors.

In the case of a narrow gap $\left(R_{i} / R_{e}>0.85 ; R_{i} / R_{e}=0.874\right.$ in our study) and for a moderately shear-thinning fluid $(n>0.3)$, Eqs. (13) and (14) can be used to calculate both viscosity and shear rate (supposed to be quite homogeneous in the gap) with an error less than $4 \%$ on shear rate:

$\eta=\frac{\Gamma}{\omega} \frac{\beta^{2}-1}{8 \pi^{2} L R_{e}^{2}\left(1+g^{2}\right)}$

$\dot{\gamma}=16 \pi \omega \frac{\beta^{2}}{(1+\beta)^{2}\left(\beta^{2}-1\right)}$

where $\Gamma$ is the steady state torque $(\mathrm{N} \mathrm{m}), \omega$ is the rotor speed (expressed in number of turns per second), $\beta=R_{e}$ / $R_{i}, R_{e}$ is the diameter of the mixing chamber (m), $R_{i}$ is the equivalent diameter $(\mathrm{m})$ of the rotors according to the double-Couette approximation, $L$ is the length of the rotors (m) and $g$ is the gear ratio between the rotors.

\subsection{Rheological modelling}

Two models are mainly used to describe the melt viscosity of PLA: the power law (Eq. (15)) and the Carreau-Yasuda models (Eq. (16)) [10]:

$\eta=K|\dot{\gamma}|^{n-1}$

where $K$ is the consistency ( $\mathrm{Pa}^{\mathrm{n}}$ ) and $n$ the power law index,

$\eta(\dot{\gamma})=\eta_{0}\left[1+(\lambda \dot{\gamma})^{a}\right]^{\frac{n-1}{a}}$ 


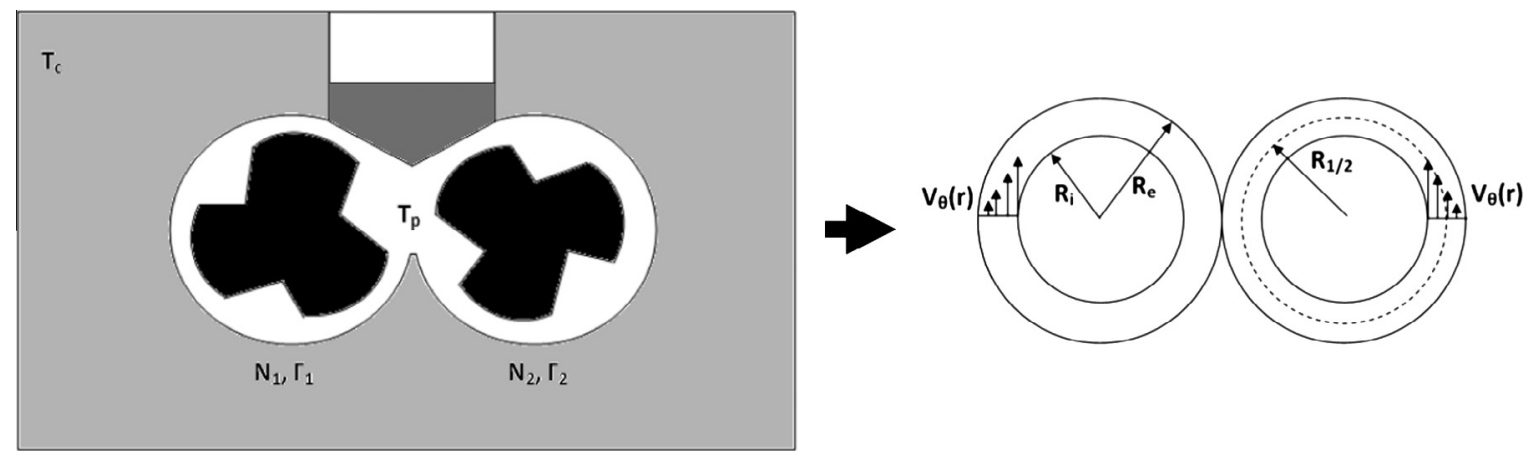

Fig. 1. Double-Couette approximation for batch mixer torque rheometry.

where $\eta_{0}$ is the zero-shear viscosity (Pa $\mathrm{s}$ ), $\lambda$ is the relaxation time corresponding to the onset of shear-thinning (s), $a$ is the Yasuda index which determines the curvature of the shear-thinning transition and $n$ is the power law index.

While the power law model successfully fits the behaviour of numerous polymers at high shear rates, it keeps some awkward features [10]. Indeed, the unit of the consistency $K$ depends on the value of the power law index $n$ and it does not use the zero-shear viscosity as a parameter and yet is not valid for low shear rates. However, it has been and is still widely used to describe viscosity due to its simplicity. This model was firstly improved by Cross [9] and Carreau [7] to yield to the present Carreau-Yasuda model when Yasuda et al. [41] finally added the Yasuda index.

In these forms, those models (power law PL2 and Carreau-Yasuda CY4, the number corresponding to the number of adjustable parameters) do not take into account the effect of temperature on viscosity. The temperature dependency of the consistency $K$ in the power-law and both Newtonian viscosity $\eta_{0}$ and relaxation time $\lambda$ in the Carreau-Yasuda model is usually described using an Arrhenius's law (Eqs. (17a), (17b) and (17c)) [25]. The activation energy $E_{a}$ or $E_{a}^{\prime}$ is then a third adjustable parameter for the power-law (PL3) and a fifth parameter in the CarreauYasuda model (CY5).

$$
\begin{aligned}
& \alpha_{T}\left(T_{P}\right)=\frac{K\left(T_{P}\right)}{K\left(T_{\text {ref }}\right)}=\exp \left[\frac{E_{a}}{R}\left(\frac{1}{T_{P}}-\frac{1}{T_{\text {ref }}}\right)\right] \\
& \alpha_{T}^{\prime}\left(T_{P}\right)=\frac{\eta_{0}\left(T_{P}\right)}{\eta_{0}\left(T_{\text {ref }}\right)}=\exp \left[\frac{E_{a}^{\prime}}{R}\left(\frac{1}{T_{P}}-\frac{1}{T_{\text {ref }}}\right)\right] \\
& \alpha_{T}^{\prime}\left(T_{P}\right)=\frac{\lambda\left(T_{P}\right)}{\lambda\left(T_{\text {ref }}\right)}=\exp \left[\frac{E_{a}^{\prime}}{R}\left(\frac{1}{T_{P}}-\frac{1}{T_{\text {ref }}}\right)\right]
\end{aligned}
$$

where $\alpha_{T}$ (or $\alpha_{T}^{\prime}$ ) is the shift factor, $E_{a}$ is the activation energy corresponding to the material relaxation $\left(\mathrm{J} \mathrm{mol}^{-1}\right)$, $R$ is the gas constant $\left(8.314 \mathrm{~J} \mathrm{~mol}^{-1} \mathrm{~K}^{-1}\right), T_{r e f}$ and $T_{P}$ are respectively the reference and the measurement temperature $(\mathrm{K})$. In the case of a power-law model, the Newtonian viscosity is simply replaced by the consistency.

In the case of a Carreau-Yasuda modelling, the effect of molar mass on melt viscosity is often taken into account in both Newtonian viscosity and relaxation time using a power law (Eqs. (18) and (19)) [15]:

$$
\begin{aligned}
& \eta_{0}=\eta_{0, \text { ref }}\left(\frac{M_{w}}{M_{w, r e f}}\right)^{\alpha} \\
& \lambda_{0}=\lambda_{0, \text { ref }}\left(\frac{M_{w}}{M_{w, \text { ref }}}\right)^{\alpha}
\end{aligned}
$$

where $\eta_{0, \text { ref }}$ is the Newtonian viscosity at the reference temperature $T_{\text {ref }}$ and molar mass $M_{w, r e f}, \alpha$ is a material constant, $M_{w}$ is the weight average molar mass $\left(\mathrm{kg} \mathrm{mol}^{-1}\right) . \alpha$ varies between 1 and 1.2 up to a critical molar mass $M_{c}$ and above it varies between 3.4 and 4.2 [15]. In the case of a power-law model, the Newtonian viscosity is also replaced by the consistency.

The exponent $\alpha$ is then a fourth adjustable parameter for the power-law (PL4) and a sixth parameter in the Carreau-Yasuda model (CY6). Eqs. (20) and (21) summarise the PL4 and CY6 models respectively.

$$
\begin{aligned}
& \eta\left(\dot{\gamma}, T, M_{w}\right)=K_{0, \text { ref }}\left(\frac{M_{w}}{M_{w, \text { ref }}}\right)^{\alpha} \exp \left[\frac{E_{a}}{R}\left(\frac{1}{T_{P}}-\frac{1}{T_{\text {ref }}}\right)\right]|\dot{\gamma}|^{n-1}(20) \\
& \eta\left(\dot{\gamma}, T, M_{w}\right)=\eta_{0, \text { ref }}\left(\frac{M_{w}}{M_{w, \text { ref }}}\right)^{\alpha} \exp \left[\frac{E_{a}^{\prime}}{R}\left(\frac{1}{T_{P}}-\frac{1}{T_{\text {ref }}}\right)\right] \\
& \quad \times\left\{1+\left(\lambda_{0, \text { ref }}\left(\frac{M_{w}}{M_{w, \text { ref }}}\right)^{\alpha} \exp \left[\frac{E_{a}^{\prime}}{R}\left(\frac{1}{T_{P}}-\frac{1}{T_{\text {ref }}}\right)\right] \dot{\gamma}\right)^{a}\right\}^{\frac{n-1}{a}}(21)
\end{aligned}
$$

Fang and Hanna [14] used a power law model to describe the rheological behaviour of an amorphous and a semicrystalline PLA at 150 and $170{ }^{\circ} \mathrm{C}$; the consistency was varying between 240,000 and $650,000 \mathrm{~Pa} \mathrm{~s}^{\mathrm{n}}$ with a pseudo plastic index varying between 0.17 and 0.30 . Schwach and Avérous [34] also used the power law model to model the rheological behaviour of PLA at 130 and $150{ }^{\circ} \mathrm{C}$. Consistency was varying between 34,000 and $90200 \mathrm{~Pa} \mathrm{~s} \mathrm{~s}^{\mathrm{n}}$ while pseudoplastic index was about 0.23 . They evaluated the activation energy at $E_{a}=67.5 \mathrm{~kJ} \mathrm{~mol}^{-1}$. Witzke [40] studied the rheological behaviour of several linear amorphous PLA with weight average molar mass varying between 75 and $400 \mathrm{~kg} \mathrm{~mol}^{-1}$. The activation energy was estimated at $E_{a}=104 \pm 13 \mathrm{~kJ} \mathrm{~mol}^{-1}$ at $T_{r e f}=175^{\circ} \mathrm{C}$ and the power law exponent describing the influence of weight average molar mass was found to be $\alpha=2.24 \pm 0.25$ with $\eta_{0 \text {,ref }}=97 \pm 18$ Pa s at $M_{w, r e f}=100 \mathrm{~kg} \mathrm{~mol}^{-1}$. Cooper-White and Mackay [8] also studied the influence of molar mass and temperature on the rheological behaviour of PLA. They found that the Newtonian viscosity varies following a power law of 
the weight average molar mass with an exponent $\alpha=4$ for molar mass higher than the critical value $M_{c}=16 \mathrm{~kg} \mathrm{~mol}^{-1}$.

Dorgan et al. [13,11], Palade et al. [28], Lehermeier and Dorgan [24], Dorgan et al. [12] studied different blends of linear and branched PLA with various $L: D$ ratio and molar mass. The activation energies of linear $(L: D$ ratio $96: 4$, weight average molar mass $M_{w}=111 \mathrm{~kg} \mathrm{~mol}^{-1}$, polydispersity index $I=2.1$ ) and branched ( $L: D$ ratio 96:4, weight average molar mass $M_{w}=149 \mathrm{~kg} \mathrm{~mol}^{-1}$, polydispersity index $I=2.9$ ) PLA were respectively $71.9 \mathrm{~kJ} \mathrm{~mol}^{-1}$ and $77.9 \mathrm{~kJ} \mathrm{~mol}^{-1}$ at $T_{r e f}=180^{\circ} \mathrm{C}$. For linear PLA with $L: D=100: 0\left(M_{w}=40\right.$ to $\left.800 \mathrm{~kg} \mathrm{~mol}^{-1}\right), L: D=98: 2\left(M_{w}=\right.$ $\left.120 \mathrm{~kg} \mathrm{~mol}^{-1}\right)$ and $L: D=96: 4\left(M_{w}=111 \mathrm{~kg} \mathrm{~mol}^{-1}\right)$, they found a power law exponent $\alpha=3.7$.

The purpose of this article is to establish the energy balance of the batch mixing process of neat PLA and to obtain the influence of each process parameter (temperature, rotor speed and mixing time) on the energy efficiency. Moreover a comparison between Bousmina's model and other more traditional methods (rotational shear and capillary rheometry) will be given.

\section{Experimental}

\subsection{Material}

The polymer used was a commercial grade of PLA from NatureWorks $^{\infty}$ LLC (Ingeo ${ }^{\mathrm{TM}}$ 7000D). Thermal properties, density and molar mass evolution during degradation were determined in a previous work [23]. Glass transition temperature $T_{g}$ is $57^{\circ} \mathrm{C}$ (this value is provided by Moldflow Plastics Labs [27] to indicate the position of the glass transition which corresponds to a temperature range [21]), melting temperature $T_{m}$ is $151^{\circ} \mathrm{C}$ and the melting enthalpy is $34.7 \mathrm{~kJ} \mathrm{~kg}^{-1}$ corresponding to a degree of crystallinity of $37 \%$ [27]. Heat capacity before and after the glass transition are respectively about 1.4 and $1.9 \mathrm{~kJ} \mathrm{~kg}^{-1}{ }^{\circ} \mathrm{C}^{-1}$ [27]. Density at room temperature is $1240 \mathrm{~kg} \mathrm{~m}^{-3}$ and the volume thermal expansion coefficient is $8.23 .10^{-4}{ }^{\circ} \mathrm{C}^{-1}$ [27].

\subsection{Mixing process}

PLA was mixed in a Haake Rheomix 3000 batch mixer using two counter-rotating rotors with a gear ratio $g$ of $2 / 3$. The mixing time $t_{m i x}$ was fixed at $10 \mathrm{~min}$ to study the influence of rotor speed $N(40,50,75,100$ and $150 \mathrm{rpm})$ and mixing temperature $T_{c}\left(170\right.$ and $\left.190{ }^{\circ} \mathrm{C}\right)$. $250 \mathrm{~g}$ of PLA was introduced in the $300 \mathrm{~cm}^{3}$ mixing chamber. Depending on the temperature in steady state (from $175^{\circ} \mathrm{C}$ to $215^{\circ} \mathrm{C}$ ), the density varies from 1050 to $1100 \mathrm{~kg} \mathrm{~m}^{-3}$ and the filling ratio between $76 \%$ and $78 \%$.

The effective equivalent radius of the rotors was determined using the calibration procedure given by Bousmina et al. [4] and was found to be $29.7 \mathrm{~mm}$ for an external radius of $34 \mathrm{~mm}$ which satisfies the narrow gap hypothesis. The length of the chamber is $84.1 \mathrm{~mm}$. Shear rate corresponding to each rotor speed was obtained using Eq. (19); in increasing order of rotor speed, it gives 30.7, $38.4,57.6,76.8$ and $115.3 \mathrm{~s}^{-1}$.
The polymer pellets were introduced into the mixing chamber when the rotors did not rotate. As soon as all the material was loaded in the mixing chamber, the trial started. The torque and the average polymer temperature were recorded during each trial but pressure evolution was not recorded.

\subsection{Parallel plate rheometer}

The samples were prepared by compression moulding (Darragon $100 \mathrm{kt}, 400 \times 400 \mathrm{~mm}^{2}$ ) at $170{ }^{\circ} \mathrm{C}, 190{ }^{\circ} \mathrm{C}$ and $210^{\circ} \mathrm{C}$ for $10 \mathrm{~min}, 20 \mathrm{~min}$ or $30 \mathrm{~min}$ thus obtaining different degradation rates. 130 bar pressure was applied during the last $3 \mathrm{~min}$ of the cycle. The plate dimension was $150 \times 150 \mathrm{~mm}^{2}$ and its thickness was $4 \mathrm{~mm}$ and it was cut into discs of $25 \mathrm{~mm}$ diameter. The weight average molar mass for each plate was determined by SEC-MALS in a previous work [23], the results are presented in Table 2.

The rheological measurements were performed on an ARES rheometer (Rheometric Scientific) using a parallel plate geometry ( $25 \mathrm{~mm}$ diameter). 2 min after the sample has been loaded, the gap is reduced from 5 to $1 \mathrm{~mm}$ and the excess of material is removed within 2 min 30 s. Every oscillatory shear test starts 2 min later, i.e. 6 min $30 \mathrm{~s}$ after the sample was loaded. Thermal stability was measured at $0.1 \mathrm{~Hz}$ for each temperature for $15 \mathrm{~min}$. At the highest temperature, the range of shear rate had to be reduced in order to shorten the trial and avoid degradation. Linear viscoelasticity region was established at $0.1 \mathrm{~Hz}$ from $0.01 \%$ to $100 \%$ strain. In order to determine the rheological behaviour and its temperature dependency, oscillatory tests were performed at $166,176,186,196$ and $206{ }^{\circ} \mathrm{C}$, at $1 \%$ strain from 0.1 to $100 \mathrm{rad} \mathrm{s}^{-1}$.

\subsection{Capillary rheometer}

The samples prepared for the ARES measurements were also used for capillary rheometry. The capillary measurements were performed between 100 and $10,000 \mathrm{~s}^{-1}$ at $180{ }^{\circ} \mathrm{C}$ on a Goettfert Rheotester 1000 (Ecole des mines de Paris, CEMEF, Sophia Antipolis, France) using several dies (1 mm diameter and various L/D ratios: 10, 20 and 30). The barrel diameter was $12 \mathrm{~mm}$ and the successive piston velocities were $0.01,0.02,0.04,0.08,0.16,0.32$, 0.64 and $1.28 \mathrm{~mm} \mathrm{~s}^{-1}$. A pressure sensor allowed to measure pressure inside the barrel between 5 and $50 \mathrm{MPa}$. The stability criterion for pressure measurement considers a relative variation lower than $5 \%$ for $10 \mathrm{~s}$. Both Bagley and Weissenberg-Rabinowitsch corrections were used to obtain the viscosity as a function of the true shear rate.

Table 2

Weight average molar mass $\left(\mathrm{kg} \mathrm{mol}^{-1}\right)$ for the different compression conditions [23].

\begin{tabular}{llll}
\hline & $10 \mathrm{~min}$ & $20 \mathrm{~min}$ & $30 \mathrm{~min}$ \\
\hline $170^{\circ} \mathrm{C}$ & 111 & - & 95 \\
$190^{\circ} \mathrm{C}$ & 102 & - & 86 \\
$210^{\circ} \mathrm{C}$ & - & 66 & 54 \\
\hline
\end{tabular}




\section{Results and discussion}

\subsection{Melt rheology}

The rheological behaviour of PLA was evaluated in order to model both influence of temperature and molar mass degradation that must be taken into account for process modelling. Fig. 2 presents the viscosity curves at different temperatures for two different weight average molar mass obtained with the ARES rheometer between 0.1 and $100 \mathrm{rad} \mathrm{s}^{-1}$.

The shift factor $\alpha_{T}^{\prime}(T)=\frac{\eta_{0}(T)}{\eta_{0}\left(T_{\text {ref }}\right)}$ is calculated at the reference temperature of $180^{\circ} \mathrm{C}$ for each temperature and molar mass. The shift factor is then expressed with the Arrhenius's law (Eq. (17b)) to obtain the activation energy; Fig. 3 presents the influence of the weight average molar mass on the activation energy. An identical average value of $85.3 \pm 13.8 \mathrm{~kJ} \mathrm{~mol}^{-1}$ for all the different molar mass will be used for the time-temperature superposition because the influence of molar mass on activation energy should not be taken into account in the Arrhenius's law if we assume Eqs. (20) and (21).

Once the time-temperature superposition is done, the Cox-Merz rule is used to add the viscosity curves obtained with the capillary rheometer between 100 and $10,000 \mathrm{~s}^{-1}$ at $180{ }^{\circ} \mathrm{C}$ (Fig. 4). The rheological behaviour is modelled using the Carreau-Yasuda model (Eq. (16)) between 0.1 and $10,000 \mathrm{~s}^{-1}$ for each molar mass, power law index $n$ and Yasuda index a were fixed for the curve fitting at 0.094 (determined from the capillary tests) and 0.69 respectively. The parameter $a$ was not fixed in a first approach and the modelling leaded to $0.69 \pm 0.02$ in every case while molar mass was not reduced below $70 \mathrm{~kg} \mathrm{~mol}^{-1}$. For lower molar mass, the results obtained for the capillary results showed an important dispersion which was due to a very low viscosity of those materials and they were not used for the modelling. Because of the lack of data, it was decided to fix the $a$ parameter in those cases. According to Fig. 4 the time-temperature superposition is rather well verified except perhaps for $66.0 \mathrm{~kg} \mathrm{~mol}^{-1}$.

The influence of molar mass on Newtonian viscosity $\eta_{0}$ and relaxation time $\lambda_{0}$ is shown in Fig. 5 and modelled using a power law (Eq. (21)), the reference molar mass was chosen at $100 \mathrm{~kg} \mathrm{~mol}^{-1}$. The slope was determined at 4.43 and 4.72

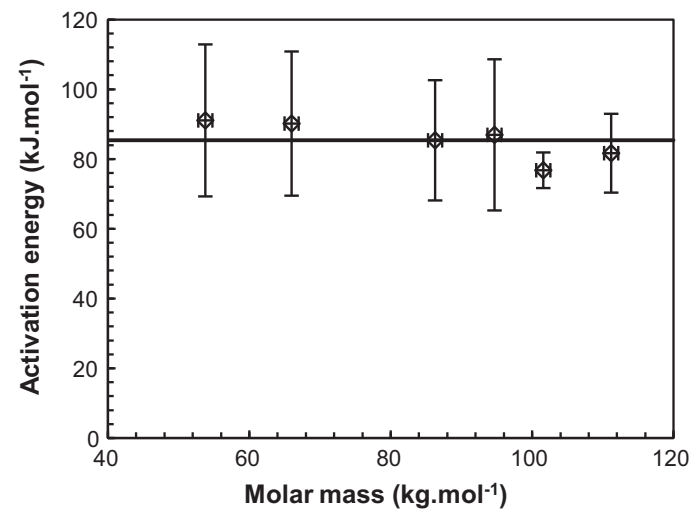

Fig. 3. Influence of weight average molecular weight on Arrhenius's law activation energy.

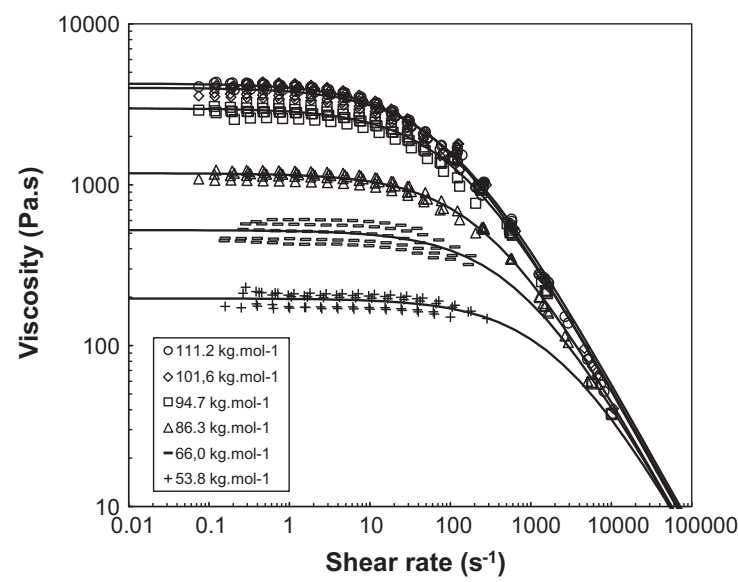

Fig. 4. Viscosity curves of various molecular weights PLA at $T_{\text {ref }}=180^{\circ} \mathrm{C}$ from parallel-plate and capillary rheometer measurements. Lines represent the Carreau-Yasuda fits.

in the case of Newtonian viscosity and relaxation time respectively. As the determination of Newtonian viscosity is more reliable than the determination of the relaxation time, the first value was used for the modelling. Table 3 summarises the different parameters used to describe the
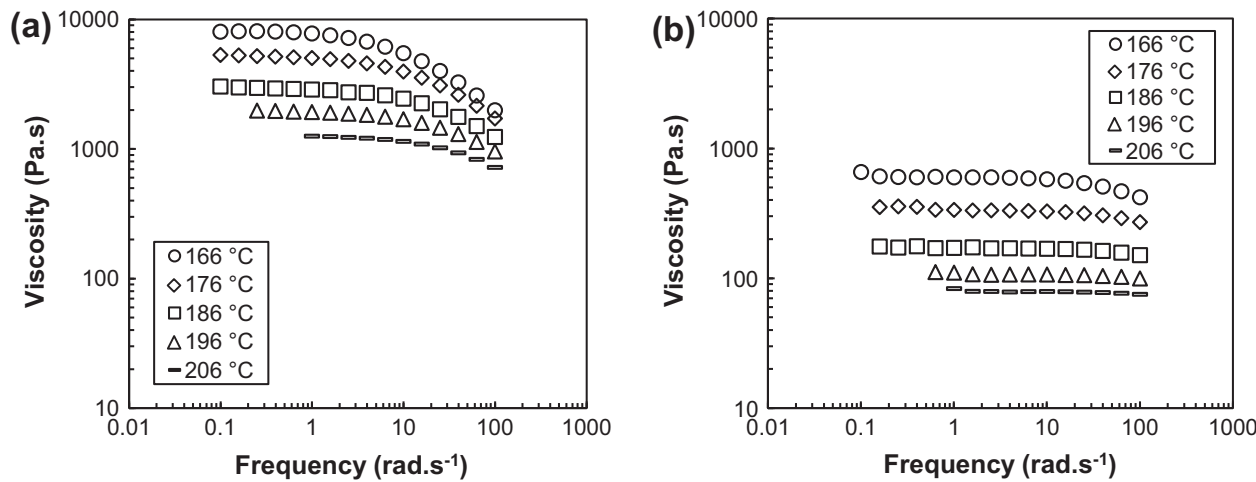

Fig. 2. Viscosity curves of PLA. (a) $M_{w}=111 \mathrm{~kg} \mathrm{~mol}^{-1}$ and (b) $M_{w}=54 \mathrm{~kg} \mathrm{~mol}^{-1}$. 

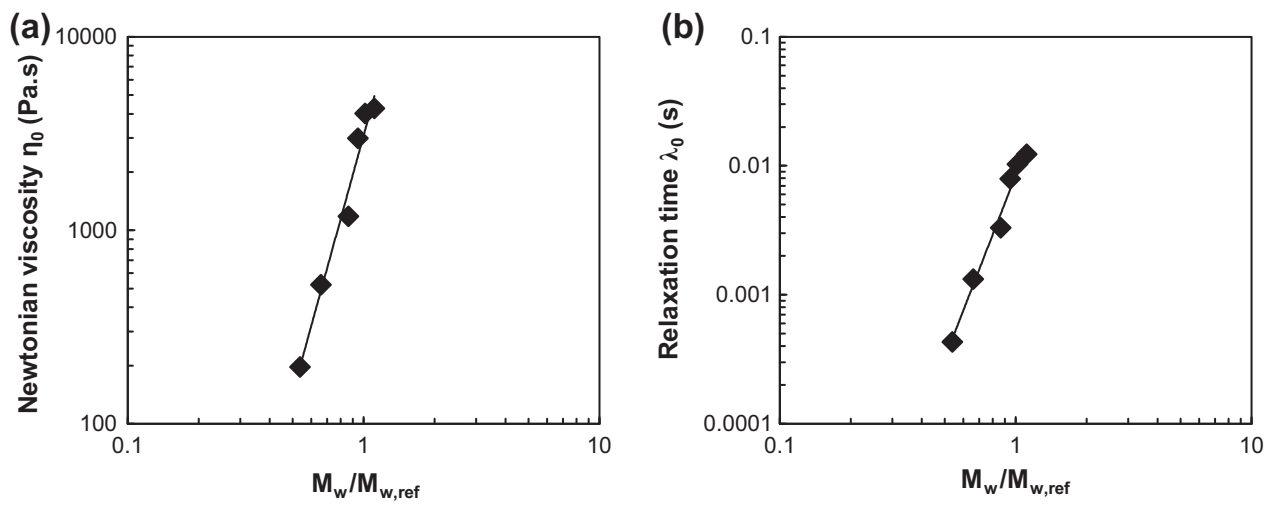

Fig. 5. Influence of weight average molecular weight on (a) Newtonian viscosity and (b) relaxation time obtained with the Carreau-Yasuda fits. Lines represent the power law fitting.

Table 3

Carreau-Yasuda parameters of PLA at reference temperature $T_{\text {ref }}=180{ }^{\circ} \mathrm{C}$ and reference weight average molar mass $M_{w, r e f}=100 \mathrm{~kg} \mathrm{~mol}^{-1}$.

\begin{tabular}{llllll}
\hline$\eta_{0, \text { ref }}($ Pa s $)$ & $\lambda_{0, \text { ref }}(\mathrm{s})$ & $E_{a}\left(\mathrm{~kJ} \mathrm{~mol}^{-1}\right)$ & $\alpha$ & $a$ & $n$ \\
\hline 3084 & 0.0084 & 85.3 & 4.43 & 0.69 & 0.094 \\
\hline
\end{tabular}

rheological behaviour and its dependency on shear rate, temperature and molar mass as defined by Eq. (21).

At high shear rate the Carreau-Yasuda tends towards a power law model with a power law index $n$. In our study the value determined previously (0.094) does not fulfil the hypothesis made to use Newtonian approximation of Bousmina's model for the mixing process (28\% error on shear rate in this case). In order to use Eqs. (8) and (9) to model the mixing process, the shear thinning behaviour of PLA must be evaluated in the range of shear rate occurring in the batch mixer ( 10 and $150 \mathrm{~s}^{-1}$ ) in order to verify if the power law index is greater than 0.3 . The rheological behaviour is then also modelled between 10 and $150 \mathrm{~s}^{-1}$ using the power law based model (Eq. (20)) in order to satisfy the Bousmina's model hypothesis. However, this range of shear rate corresponds to the transition between the Newtonian behaviour and the shear thinning behaviour; the onset of shear thinning being also dependent on the temperature, the slope in the shear-thinning region, i.e. the average power law index also varies with the temperature. Moreover, the curvature of the transition region cannot be described with a power law which limits the validity of this modelling. Fig. 6 shows the influence of weight average molar mass and temperature on both power law parameters between 10 and $150 \mathrm{~s}^{-1}$. The power law index varies between 0.5 and 1 in the defined range of shear rate and temperature. The hypothesis of a moderately shear-thinning fluid is then validated $(n>0.3)$. The Arrhenius's fit on the consistency gives an activation energy $E_{a}=97.6 \pm 5.0 \mathrm{~kJ} \mathrm{~mol}^{-1}$ which is slightly higher than the value obtained from the viscosity in the Newtonian plateau.

Fig. 7 shows the influence of weight average molar mass on the consistency at the reference temperature, the power law fit gives an equivalent slope as previously $(\alpha=4.42)$ with a consistency at reference temperature and weight average molar mass of $5110 \mathrm{~Pa} \mathrm{~s}^{\mathrm{n}}$.

\subsection{Mixing process}

\subsubsection{Data correction}

At least four trials were made for each couple of temperature and rotor speed [T; N]. In order to calculate an
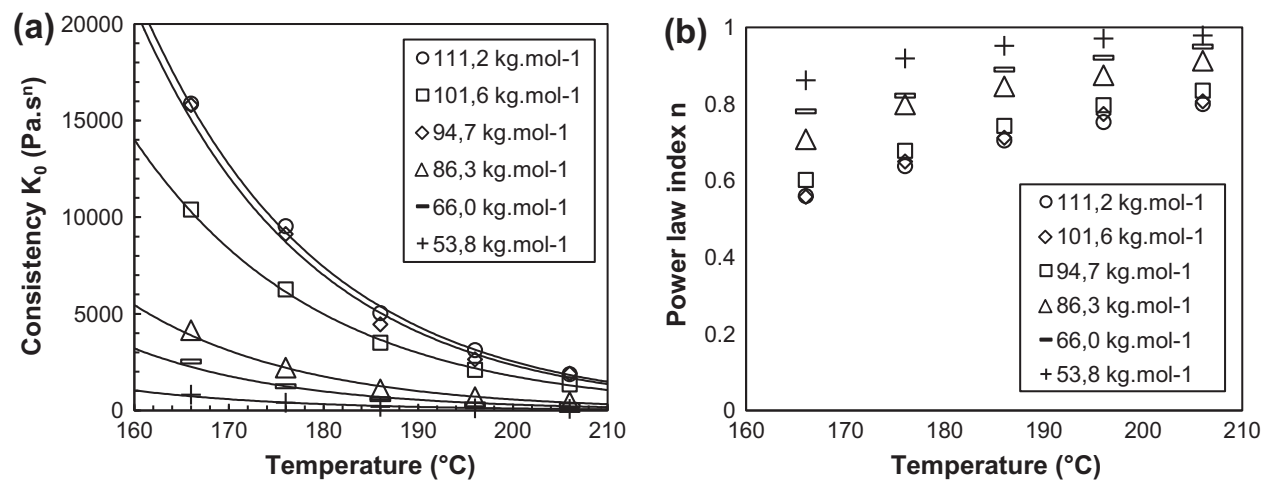

Fig. 6. (a) Consistency and (b) power law index as a function of temperature and weight average molecular weight. Lines on graph (a) represent the Arrhenius's fits. 


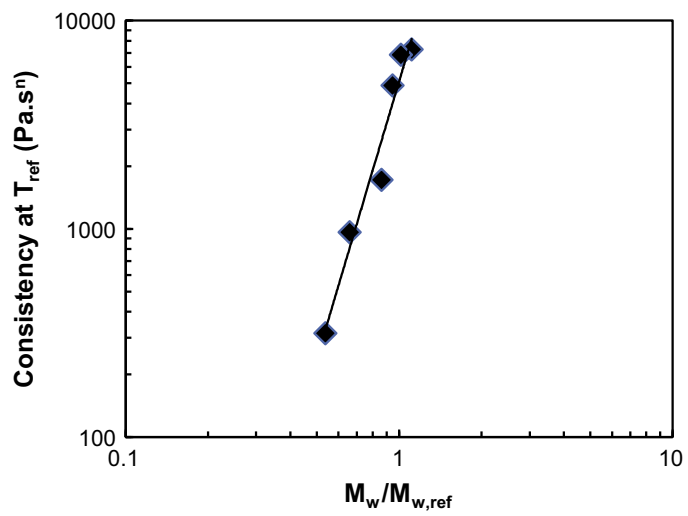

Fig. 7. Influence of weight average molecular weight on the consistency at the reference temperature $T_{r e f}=180^{\circ} \mathrm{C}$.

average torque without reducing the peak height, it was necessary to calculate an average peak time and to readjust on time scale all the data using this value. An average torque is then calculated and smoothed by calculating a local average on seven time steps.

Temperature data are used to separate the melting phase (transient state) from the mixing phase (steady state). When the polymer temperature reaches the chamber temperature $T_{c}$, we consider that the melting phase is over $\left(t=t_{1}\right)$. However, the measurement of temperature during the melting phase is not reliable (Fig. 8) and needs to be corrected. In

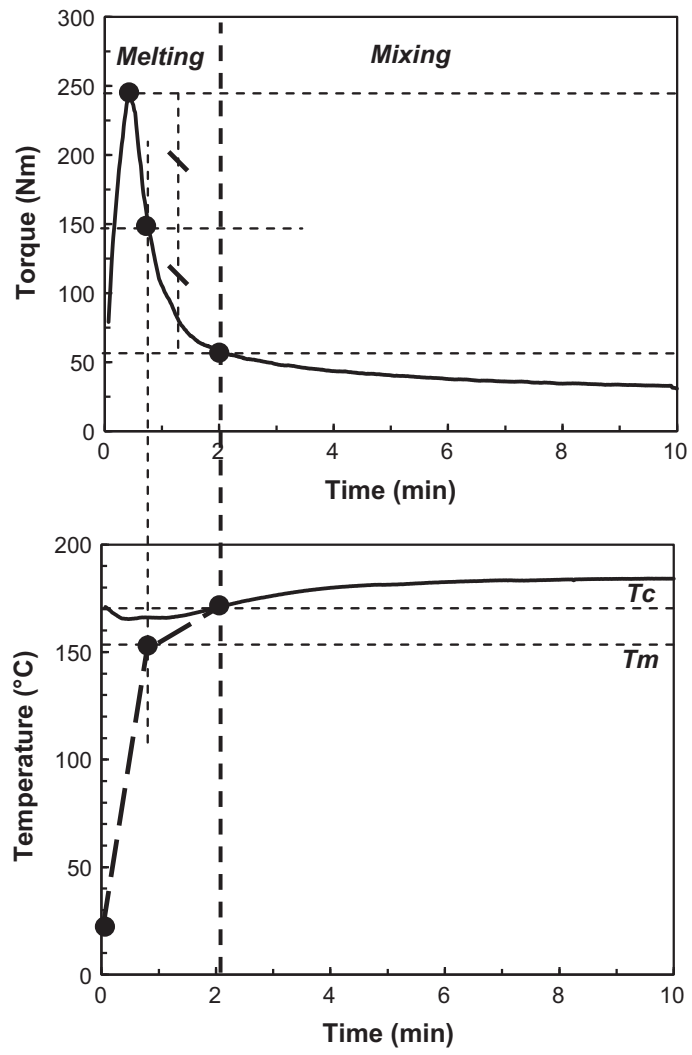

Fig. 8. Data correction for process modelling. order to do that, we consider that the polymer is at the melting temperature when the torque falls to $\Gamma\left(t_{\text {melt }}\right)=$ $\left[\Gamma\left(t_{\text {peak }}\right)+\Gamma\left(t_{1}\right)\right] / 2$; indeed, one can then suppose that half of the polymer has melt and that its average temperature is the melting temperature.

\subsubsection{Double-Couette approximation}

Viscosity is calculated using Eq. (8) and Fig. 9 presents its evolution during mixing for different rotor speeds and temperatures. It is not calculated during the melting phase because it is necessary to assume that the entire polymer is in molten state in order to use Bousmina's model. It can be noticed here that the melting phase is greatly shortened with an increasing rotor speed (the end of the melting phase corresponds for a given rotor speed to the time at the beginning of the curve) but is less affected by temperature confirming that melting is mainly induced by dissipative processes. It appears that the viscosity decreases when the chamber temperature increases and a similar trend is observed for the rotor speed. It can be also noticed that viscosity does not reach a plateau in steady-state which is probably due to the degradation occurring during mixing.

Eqs. (20) and (21) were also used to predict the evolution of viscosity over mixing taking into account the variation of temperature and weight average molar mass using the parameters obtained with the conventional rheometers. The evolution of weight average molar mass over mixing was modelled using Wachsen's model using the parameters presented in Table 1 . In order to take into account the self-heating induced by the viscous dissipation, the experimental measurement of temperature was used.

Fig. 10 shows the correlation between Bousmina's model and modelled (power law, Carreau-Yasuda) viscosities. It appears that both models (named CY6 (ARES) and PL4 (ARES)) with those parameters do not fit correctly the curves, especially at $170^{\circ} \mathrm{C}$ where viscosity is greatly overestimated. The weak correlation is explained by the lack of precision of molar mass measurements (about 10\%). It has two consequences: (1) an error on molar mass prediction will influence the viscosity with a 4.43 power (according to Eq. (21)) and (2) Newtonian viscosity and relaxation time (CY6) or consistency (PL4) at reference molar mass are the most important parameters for each model and their values also depend on weight average molar mass determination precision. In order to compensate the effect of molar mass uncertainty on rheological behaviour, those significant parameters were optimised to obtain a better correlation with Bousmina's model. In the two cases, the minimisation of the least squares residual is made with Matlab ${ }^{\boxplus 2010 a}$ using a nonlinear multivariable optimisation function based on a Nelder-Mead simplex algorithm. The optimised values of Newtonian viscosity and relaxation time for Carreau-Yasuda modelling are respectively $3780 \mathrm{~Pa}$ s and $0.0539 \mathrm{~s}$. The optimised consistency for power-law modelling is $7530 \mathrm{~Pa} \mathrm{~s}^{\mathrm{n}}$ for a power law index of 0.58. CY6 model with optimised parameters shows a good correlation with viscosity calculated according to Bousmina's model whatever the rotor speed and mixing temperature (see Fig. 10 CY6 (optim) and PL4 (optim) models). The optimisation made with the PL4 model tends to underestimate the viscosity when the rotor speed and temperature are increased. 

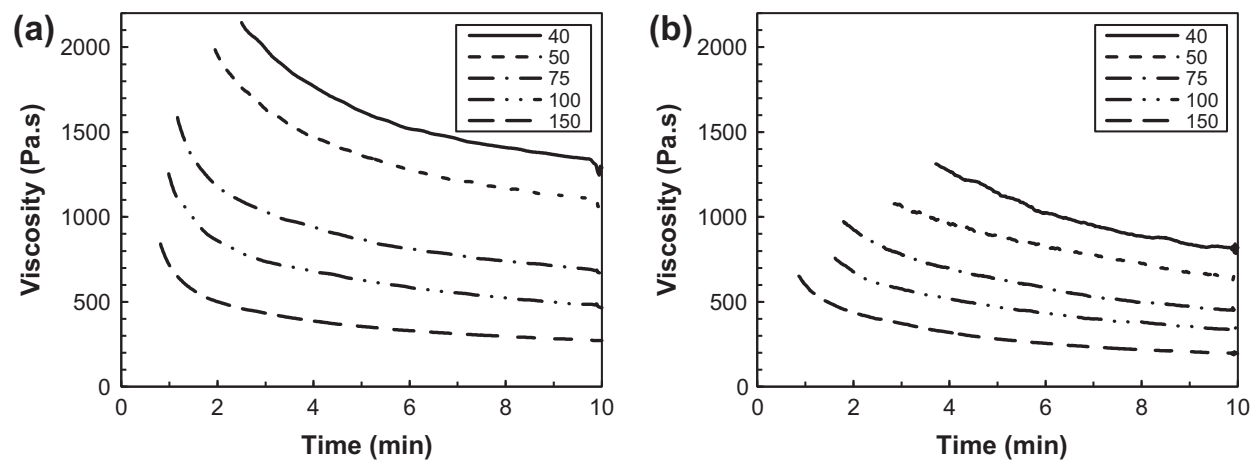

Fig. 9. Evolution of viscosity during mixing at various rotor speeds (rpm) at (a) $170^{\circ} \mathrm{C}$ and (b) $190{ }^{\circ} \mathrm{C}$.
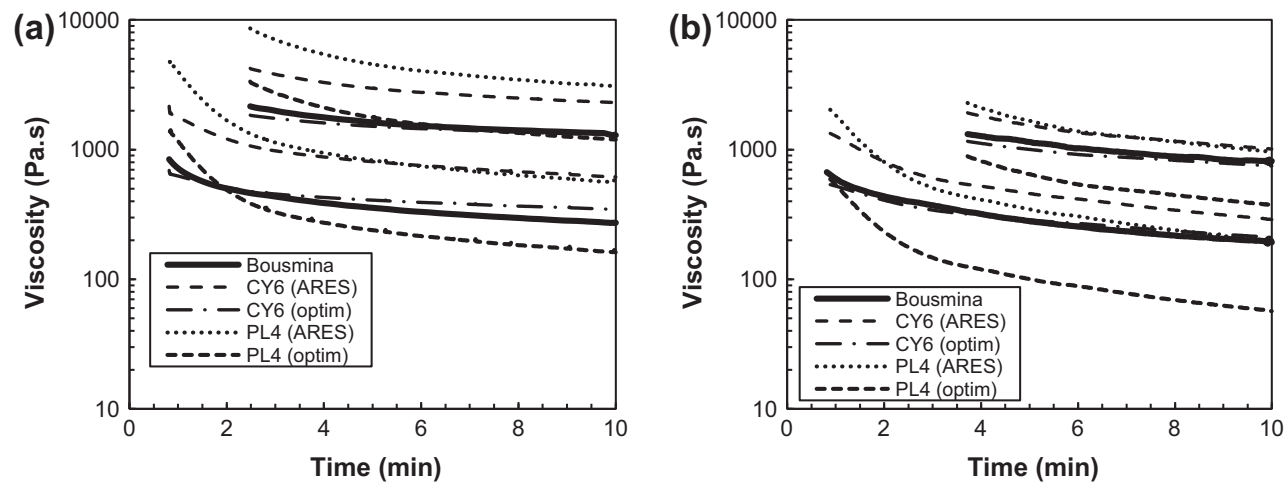

Fig. 10. Comparison of the different models at 40 (upper curves) and $150 \mathrm{rpm}$ (downer curves) at (a) $170{ }^{\circ} \mathrm{C}$ and (b) $190{ }^{\circ} \mathrm{C}$.

\subsubsection{Estimation of heat transfer in steady-state}

The viscous dissipation $\left(W=\eta \dot{\gamma}^{2} V_{P}\right.$ where $V_{p}$ is the volume of molten polymer, if we assume the shear rate to be quite homogeneous in the narrow gap between the rotors and the wall of the mixing chamber) is estimated using viscosity and shear rate calculations. The variation of polymer volume is taken into account using the volume thermal expansion coefficient. As expected, viscous dissipation increases with increasing rotor speed and decreases with temperature.

Eqs. (11) and (14) are used to calculate the heat transfer coefficient between the wall of the mixing chamber and the polymer. Practically, it was not possible to measure in a repeatable way the temperature at the rotors surface at the end of the trials because of the presence of polymer on it; as a result Eq. (12) could not be used. The hypothesis corresponding to Eq. (10) considers that there is no exchange between the rotors and the polymer; which is obviously not realistic. Fig. 11 shows the calculated values of convective heat transfer coefficient during the five last minutes of the trial for different rotor speeds at each temperature. The heat transfer coefficient is not significantly affected by the process parameters. It seems to tend towards a limit value after $10 \mathrm{~min}$. This shows that the steady state in terms of thermal exchange is not yet reached. An average convective heat transfer coefficient of $3090 \mathrm{~W} \mathrm{~m}^{-2} \mathrm{~K}^{-1}$ was estimated on the three last minutes of the trials and used for the calculation of STE. This value is much higher than the values between 500 and $1500 \mathrm{~W} \mathrm{~m}^{-2} \mathrm{~K}^{-1}$ reported in the literature for twin-screw extrusion [38]. It could be explained by higher thermal exchange occurring at the rotors surface as they are not regulated. The temperature at the surface of the rotors was measured before and after the trials using a laser pyrometer and was found to increase about $10-30{ }^{\circ} \mathrm{C}$ during mixing.

\subsubsection{Specific mechanical and thermal energy input}

SME is calculated using Eq. (6). Fig. 12 shows the influence of both parameters $(T ; \omega)$ on the input of mechanical energy. SME increases with the rotor speed but decreases when the chamber temperature is increased. SME increases faster during the melting phase than during the mixing phase.

STE is calculated using an expression equivalent to Eq. (7) in which the rotors and walls have the same temperature surface (which is the set mixing temperature) and convective heat transfer coefficient. Fig. 13 presents the evolution of STE during mixing for different rotor speeds and mixing temperatures; it clearly appears that STE increases until the end of the melting phase and decreases during the mixing phase due to a polymer temperature higher than the chamber temperature. The hypothesis of a convective heat transfer during the melting phase is not very realistic because the molten polymer does not fill the mixing chamber. However, in first approximation, the 

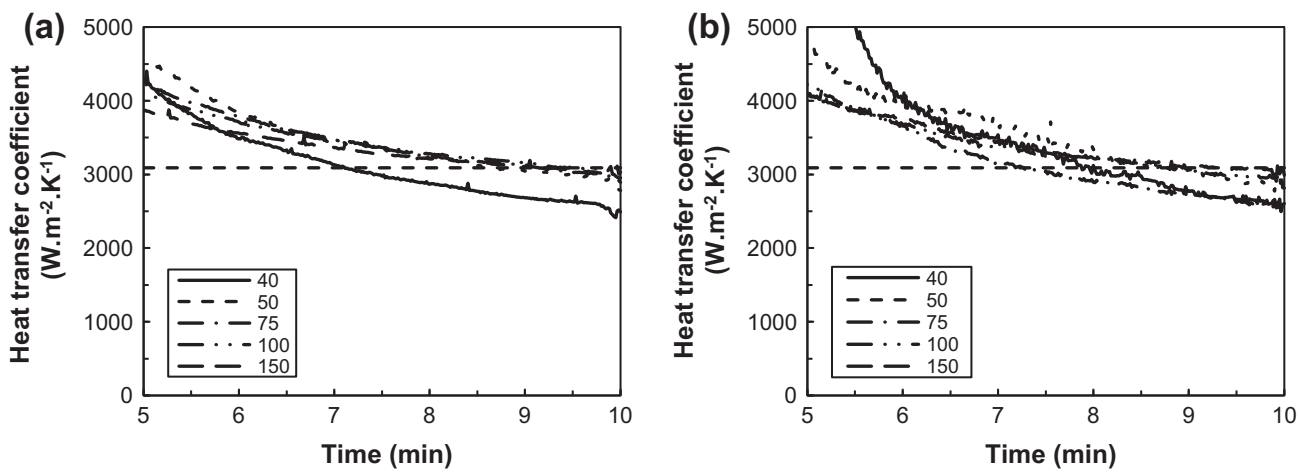

Fig. 11. Convective heat transfer coefficient at the chamber surface at different rotor speeds from 40 to $150 \mathrm{rpm}$ at (a) $170{ }^{\circ} \mathrm{C}$ and (b) $190{ }^{\circ} \mathrm{C}$.
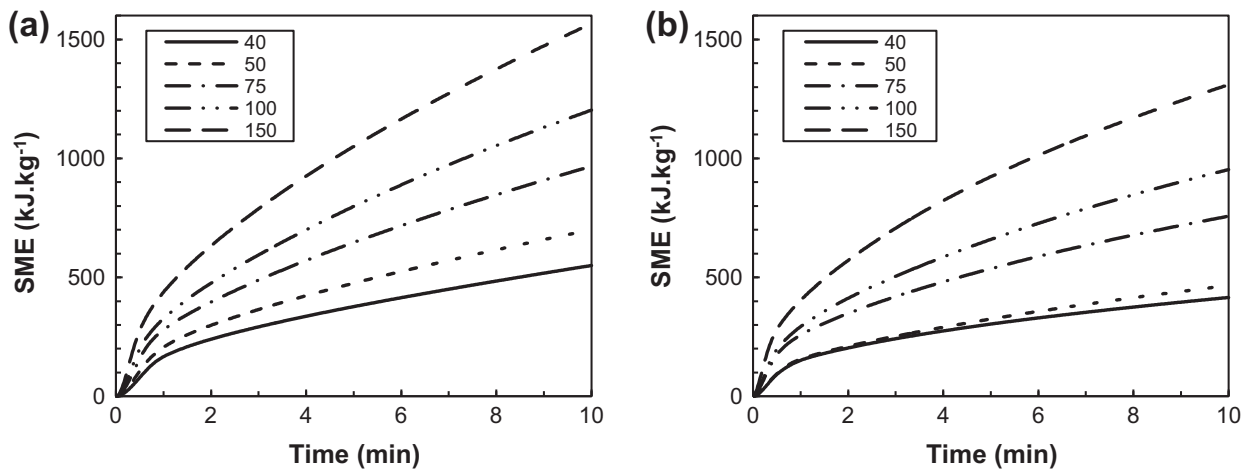

Fig. 12. SME input for PLA mixing at various rotor speed (rpm) at (a) $170{ }^{\circ} \mathrm{C}$ and (b) $190{ }^{\circ} \mathrm{C}$.
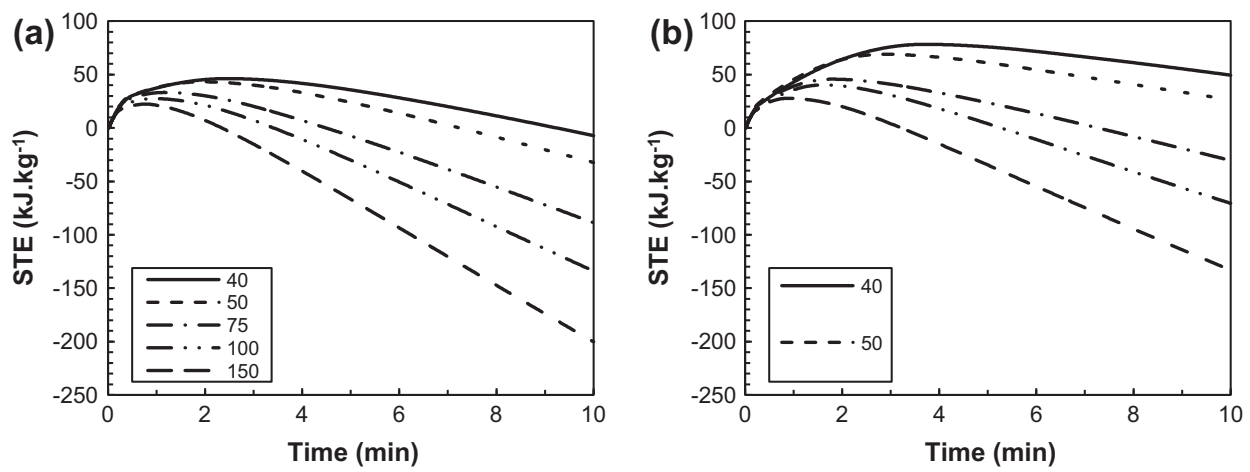

Fig. 13. STE input as a function of time at different rotor speeds from 40 to $150 \mathrm{rpm}$ at (a) $170{ }^{\circ} \mathrm{C}$ and (b) $190{ }^{\circ} \mathrm{C}$.

same heat transfer coefficient can be used for the two phases. A further improvement could be to estimate the heat transfer during melting in terms of conductive thermal exchange at the pellet surface, the diameter of the solid pellet decreasing with increase of pellet temperature [30]. STE at the end of melting phase is slightly reduced by the increase of rotor speed and the thermal energy dissipated during the mixing phase is sharply increased. This is due to an increasing shear rate (proportional to the rotor speed) that also increases the polymer self-heating. The increase of the mixing temperature tends to decrease this dissipation of thermal energy.

\subsubsection{Energy balance and energy efficiency}

Fig. 14 presents the repartition of energy input for the different rotor speeds and temperatures. It varies between 400 and $1400 \mathrm{~kJ} \mathrm{~kg}^{-1}$ which is lower than the values ranging from 1400 and $1900 \mathrm{~kJ} \mathrm{~kg}^{-1}$ reported in the literature for twin-screw extrusion [20]. It can be observed that the total energy consumption is strongly increased with an increasing rotor speed while it slightly decreases with an increasing temperature. The total energy input during the melting phase (addition of melting thermal and mechanical energy) is not significantly affected by the process parameters and remains constant about $350 \pm 40 \mathrm{~kJ} \mathrm{~kg}^{-1}$. 

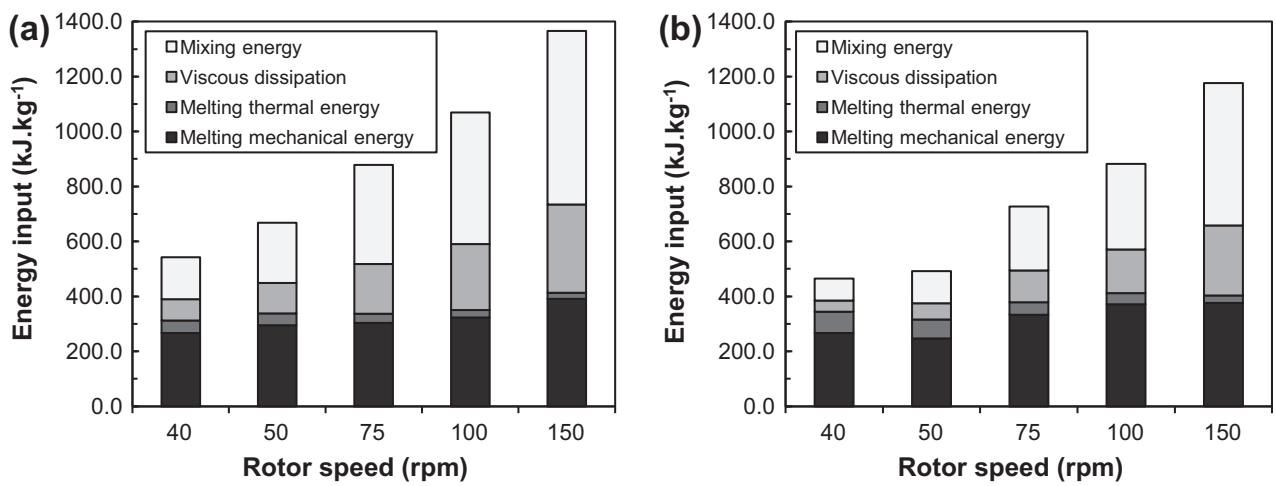

Fig. 14. Repartition of total energy input as a function of rotor speed at (a) $170{ }^{\circ} \mathrm{C}$ and (b) $190{ }^{\circ} \mathrm{C}$ after $10 \mathrm{~min}$ mixing.

Table 4

Energy efficiency of PLA melting at various rotor speeds and temperatures.

\begin{tabular}{llllll}
\hline$(\mathrm{T} ; \mathrm{N})\left({ }^{\circ} \mathrm{C}\right)$ & $40 \mathrm{rpm}$ & $50 \mathrm{rpm}$ & $75 \mathrm{rpm}$ & $100 \mathrm{rpm}$ & $150 \mathrm{rpm}$ \\
\hline 170 & 0.95 & 0.88 & 0.88 & 0.84 & 0.71 \\
190 & 1 & 1.09 & 0.91 & 0.83 & 0.84 \\
\hline
\end{tabular}

This value is very close to the theoretical energy consumed by the polymer (expressed by the numerator of Eq. (9)) which is estimated at 295 and $345 \mathrm{~kJ} \mathrm{~kg}^{-1}$ for mixing temperatures at 170 and $190{ }^{\circ} \mathrm{C}$ respectively. The ratio of mechanical energy input over total energy input during the melting phase varies between $75 \%$ and $95 \%$ depending on the process parameters. As expected, it is increased with an increasing rotor speed and decreased with an increasing temperature. The total energy input during the mixing phase varies from 50 to $1000 \mathrm{~kJ} \mathrm{~kg}^{-1}$. It increases with an increasing rotor speed and it decreases with an increasing temperature confirming that energy consumption during mixing is a function of shear stress. The ratio between melting and mixing energy varies between 0.4 and 2.9 depending on process parameters. STE (Specific Thermal Energy input based on Eq. (7)) during the mixing phase represents in every case 33\% of the total energy input during the mixing phase. This energy is considered equal to viscous dissipation assuming steady state (STE is named viscous dissipation in Fig. 14). The last part for mixing phase is SME (Specific Mechanical Energy input based on Eq. (1)) and named mixing energy in Fig. 14.

Energy efficiency at the end of the melting phase for each couple of parameters $T$ and $\omega$ is calculated according to Eq. (9) and presented in Table 4. It can be noticed that the efficiency of the melting phase increases with the mixing chamber temperature whether it decreases when the rotor speed is increased. It is supposed that the energy lost during the melting phase is partially dissipated through vibrations of the mixing chamber that become really important when the rotor speed is increased. Those values are close to 1 in every case (even higher in some cases), showing that the criterion chosen to separate the melting and the mixing phases is rather good (i.e. the polymer temperature measured by a probe reaches the mixing set temperature). However, in some cases, it was impossible to find the point at which the separation is made because the temperature measurement was always above the mixing temperature and it was necessary to set it somehow arbitrarily. In order to avoid this difficulty and to be sure that the calculated efficiency is never greater than one, it would be possible to set the separation between melting and mixing based on an energetic criterion, i.e. mixing starts when the total energy input reaches the energy consumed by the polymer to reach the mixing set temperature, but this supposes to neglect the energy losses due to the vibrations of the mixing chamber occurring during the melting phase at high rotor speeds.
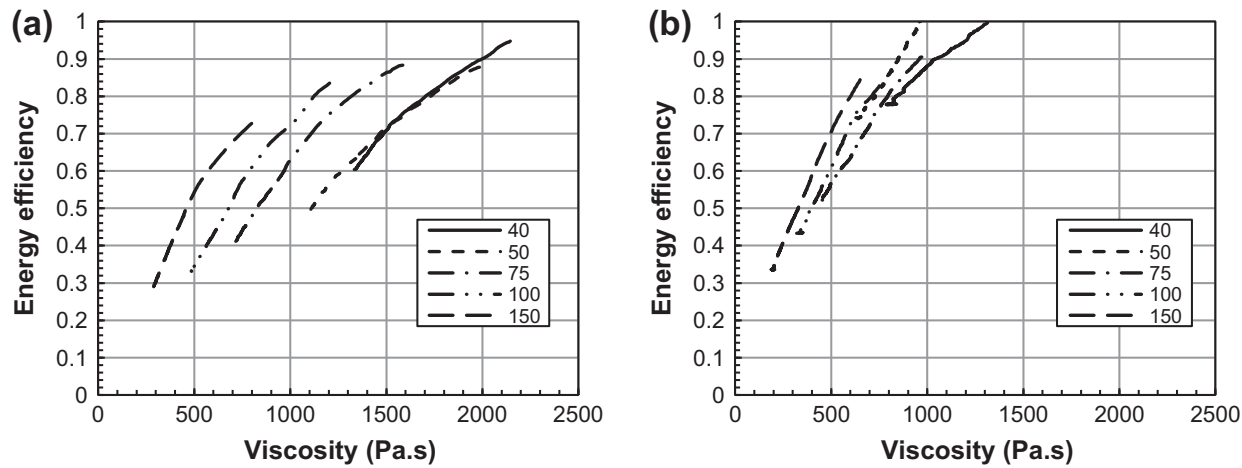

Fig. 15. Energy efficiency for the mixing process at various rotor speeds from 40 to $150 \mathrm{rpm}$ at (a) $170{ }^{\circ} \mathrm{C}$ and (b) $190{ }^{\circ} \mathrm{C}$ as a function of polymer viscosity. 
Fig. 15 shows the variation of efficiency as a function of viscosity (estimated according to Bousmina's model) during the mixing phase. We consider here that the theoretical energy required for mixing is zero since the polymer is not filled. So we calculate the mixing efficiency according to Eq. (9) considering the SDE at the end of the melting phase as a reference. The mixing efficiency at time $t$ is then obtained by the ratio between SDE at end of melting phase and SDE at time $t$ during the mixing phase. It appears that for a given chamber temperature and an increasing rotor speed, the efficiency curve is shifted towards the low viscosities and inferior levels of efficiency and still keeps the same slope. Oppositely, for a given screw speed and an increasing chamber temperature, the efficiency increases and the viscosity decreases. The slopes of the curves are also stronger. It would be possible to imagine the use of "shift factors" to obtain "master curves" of energy efficiency for every rotor speed and mixing temperature. For a given viscosity, the energy efficiency is increased with the rotor speed and temperature. It is then possible to optimise the process parameters considering that viscosity needs to be as low as possible to obtain an efficient mixing, degradation must be limited and energy efficiency must be maximised.

\section{Conclusion}

A method to determine the complete energy balance of the melting and mixing processes in a batch mixer was proposed. This method is based on the determination of viscosity and shear rate in the batch mixer proposed by Bousmina et al. [4] and allowing the estimation of the viscous dissipation in the mixer. It was supposed that, in steady state, the viscous dissipation is compensated by the heat transfer through the wall surface and this assumption was used to determine an equivalent convective heat transfer coefficient at the wall surface. The overall energy balance could then be obtained.

In the case of neat PLA mixing, it was found that the energy consumption is increased with an increasing rotor speed and decreased with an increasing temperature. The energy consumed for the melting of the polymer pellets is not strongly affected by the process parameters and the energy efficiency of the melting phase is closed to 1 . The small decrease of energy efficiency observed when rotor speed was increased was related to the important vibrations of the mixing chamber during the melting phase. A new criterion based on energy to separate the melting phase and the mixing phase could be proposed to overcome this problem: the end of melting occurring when energy input reaches the SDE. A method to optimise the process parameters was proposed from the curves of energy efficiency versus viscosity. Viscosity must be minimised to obtain a good mixing, considering that degradation must be limited and energy efficiency maximised.

The rheological behaviour was also determined using traditional rheometers in order to be compared to the curves obtained using Bousmina's model. This behaviour was described using both power-law and Carreau-Yasuda models. A large overestimation was observed especially at lower temperatures and it was attributed to the lack of precision on the measurement of weight average molar mass used to determine the parameters of the degradation model and some parameters of the rheological models. Newtonian viscosity and relaxation time in Carreau-Yasuda model and consistency in power-law model were optimised to fit the curves.

This work is a preliminary and necessary step in the study of mixing efficiency of thermoplastic composites compounding either with a twin-screw extruder or an internal mixer.

\section{References}

[1] Avérous L. Polylactic acid synthesis properties and applications. In Belgacem MN, Gandini A, editors. Monomers, polymers and composites from renewable resources. Amsterdam: Elsevier; 2008. p. 433-50.

[2] Bismarck A, Mohanty AK, Aranberri-Askargorta I, Czapla S, Misra M, Hinrichsen G, et al. Surface characterization of natural fibers; surface properties and the water up-take behavior of modified sisal and coir fibers. Green Chem 2001;3:100-7. http://dx.doi.org/10.1039/ b100365h.

[3] Bismark A, Mishra S, Lampke T. Plant fibers as reinforcement for green composites. In: Mohanty AK, Misra M, Drzal LT, editors. Natural fibers, biopolymers and biocomposites. New York: Taylor \& Francis; 2005. p. 36-112. http://dx.doi.org/10.1201/9780203508206.ch2.

[4] Bousmina M, Ait-Kadi A, Faisant JB. Determination of shear rate and viscosity from batch mixer data. J Rheol 1999;43:415-33. http:// dx.doi.org/10.1122/1.551044.

[5] Brostow W, Datashvili T, Miller H. Wood and wood derived materials. J Mater Ed 2010;32:125-38.

[6] Carrasco F, Pagès P, Gámez-Pérez J, Santana OO, Maspoch ML Processing of poly(lactic acid): characterization of chemical structure, thermal stability and mechanical properties. Polym Degrad Stabil 2010;95:116-25. http://dx.doi.org/10.1016 j.polymedegradstab.2009.11.045.

[7] Carreau PJ. Rheological equations from molecular network theory Trans Soc Rheol 1972;16:99-127.

[8] Cooper-White JJ, Mackay ME. Rheological properties of poly(lactides) Effect of molecular weight and temperature on the viscoelasticity of poly(l-lactic acid).. J Polym Sci B Polym Phys 1999;37:1803-14. http://dx.doi.org/10.1002/(SICI)1099-0488(19990801)37:15<1803:: AID-POLB5>3.0.CO;2-M

[9] Cross MM. Analysis of flow data on polymer systems under steady or oscillatory shear. In: Wetton RE, Whorlow RW, editors. Polymer systems: deformation and flow proceedings of the 1966 annual conference of the British society of rheology macmillan. London; 1968. p. 263-73.

[10] Dealy JM, Wissbrun KF. Melt rheology and its role in plastics processing - theory and applications. 1st ed. New York: Van Nostrand Reinhold; 1990.

[11] Dorgan JR, Lehermeier HJ, Mang M. Thermal and rheological properties of commercial-grade poly(lactic acid)s. J Polym Environ 2000;8:1-9. http://dx.doi.org/10.1023/A:1010185910301.

[12] Dorgan JR, Janzen J, Clayton MP. Melt rheology of variable L-content poly(lactic acid). J Rheol 2005;49:607-19. http://dx.doi.org/10.1122/ 1.1896957.

[13] Dorgan JR, Williams JS, Lewis DN. Melt rheology of poly(lactic acid): Entanglement and chain architecture effects. J Rheol 1999;43: 1141-55. http://dx.doi.org/10.1122/1.1896957.

[14] Fang Q, Hanna MA. Rheological properties of amorphous and semicrystalline polylactic acid polymers. Ind Crops Prod 1999;10:47-53. http://dx.doi.org/10.1016/S0926-6690(99)00009-6.

[15] Ferry JD. Viscoelastic properties of polymers. 3rd ed. NewYork: Wiley; 1980.

[16] Gandini A, Belgacem MN. The state of art. In: Belgacem MN, Gandini A, editors. Monomers, polymers and composites from renewable resources. Amsterdam: Elsevier; 2008. p. 1-16.

[17] Garlotta D. A literature review of poly(lactic acid). J Polym Environ 2001;9:63-84. http://dx.doi.org/10.1023/A:1020200822435.

[18] Gogolewski S, Mainil-Varlet P. The effect of thermal treatment on sterility, molecular and mechanical properties of various polylactides, 1 Poly(L-lactide). Biomaterials 1996;17:523-8. http:// dx.doi.org/10.1016/0142-9612(96)82727-X. 
[19] Gogolewski S, Javanovic M, Perren SM. The effect of melt-processing on the degradation of selected polyhydroxyacids: polylactides, polyhydroxybutyrate, and polyhydroxybutyrate-co-valerates. Polym Degrad Stabil 1993;40:313-22. http://dx.doi.org/10.1016/ 0141-3910(93)90137-8.

[20] Joosten LAJ. Process data descriptions for the production of synthetic organic materials - input data for the MATTER study. department of science, technology and society. Utrecht: Utrecht University; 1998.

[21] Kalogeras IM, Hagg Lobland HE. The nature of the glassy state: structure and glass transitions". J Mater Edu 2012;34:69-94.

[22] Kopinke FD, Remmler M, Mackenzie K, Möder M, Wachsen O. Thermal decomposition of biodegradable polyesters - II. Poly(lactic acid). Polym Degrad Stabil 1996;53:329-42. http://dx.doi.org/ 10.1016/0141-3910(96)00102-4.

[23] Le Marec PE. Modélisation du mélangeage à l'état fondu de biocomposites PLA/fibres de cellulose. Ph.D. Dissertation. France: University of Montpellier 2; 2011.

[24] Lehermeier HJ, Dorgan JR. Melt rheology of poly(lactic acid): consequences of blending chain architectures. Polym Eng Sci 2001;41:2172-84. http://dx.doi.org/10.1002/pen.10912.

[25] Lim LT, Auras R, Rubino M. Processing technologies for poly(lactic acid). Prog Polym Sci 2008;33:820-52. http://dx.doi.org/10.1016/ j.progpolymsci.2008.05.004.

[26] Maharana T, Mohanty B, Negi YS. Melt-solid polycondensation of lactic acid and its biodegradability. Prog Polym Sci 2009;34:99-124. http://dx.doi.org/10.1016/j.progpolymsci.2008.10.001.

[27] Moldflow Plastics Labs. Moldflow material testing report. MAT2238, NatureWorks ${ }^{\circledR}$ PLA 7000D. <http://www.natureworksllc.com/ /media/ Technical_Resources/Properties_Documents/PropertiesDocument_ 7000DMoldFlowReport_pdf.pdf>; 2007 [accessed 02.10.14].

[28] Palade LI, Lehermeier HJ, Dorgan JR. Melt rheology of high L-content poly(lactic acid). Macromolecules 2001;34:1384-90. http:// dx.doi.org/10.1021/ma001173b.

[29] Patel M, Narayan R. How sustainable are biopolymers and biobased products? The hope, the doubts and the reality. In: Mohanty AK, Misra M, Drzal LT, editors. Natural fibers, biopolymers and biocomposites. New York: Taylor \& Francis; 2005.

[30] Potente H, Kretschmer K. "Simulation and evaluation of compounding processes”. Macromol Mater Eng 2002;287:758-72. http://dx.doi.org/10.1002/mame.200290005.
[31] Qian B, Gogos CG. The importance of plastic energy dissipation (PED) to the heating and melting of polymer particulates in intermeshing co-rotating twin-screw extruders. Adv Polym Technol 2000;19:287-99. http://dx.doi.org/10.1002/1098-2329(200024)19: 4<287::AID-ADV5>3.0.CO;2-K.

[32] Redl A. Matériaux thermoplastiques à base de protéines de blé: Mise en forme et étude des propriétés. Ph.D. Dissertation. France: University of Montpellier 2;1998.

[33] Rudnik E. Compostable polymer materials. 1st ed. Amsterdam: Elsevier; 2008.

[34] Schwach E, Avérous L. Starch-based biodegradable blends: morphology and interface properties. Polym Int 2004;53:2115-24. http://dx.doi.org/10.1002/pi.1636.

[35] Shen L, Patel M. Life cycle assessment of polysaccharide materials: a review. J Polym Environ 2008;16:154-67. http://dx.doi.org/10.1007/ s10924-008-0092-9.

[36] Södergård A, Stolt M. "Properties of lactic acid based polymers and their correlation with composition”. Prog Polym Sci 2002;27:1123-63. http://dx.doi.org/10.1016/s0079-6700(02)00012-6.

[37] Taubner V, Shishoo R. Influence of processing parameters on the degradation of poly(L-lactide) during extrusion. J Appl Polym Sci 2001;79:2128-35. http://dx.doi.org/10.1002/1097-4628(20010321) 79:12<2128::AIDAPP1020>3.0.CO;2-\#

[38] Vergnes B, Chapet M. Extrusion - Procédés d'extrusion bi-vis. Techniques de l'ingénieur. AM 3653; 2001.

[39] Wachsen O, Platkowski K, Reichert KH. Thermal degradation of polyl-lactide -studies on kinetics, modelling and melt stabilisation. Polym Degrad Stabil 1997;57:87-94. http://dx.doi.org/10.1016/ S0141-3910(96)00226-1.

[40] Witzke DR. Introduction to properties, engineering, and prospects of polylactide polymers. Ph.D. Dissertation. Michigan State University; 1997.

[41] Yasuda K, Armstrong RC, Cohen RE. Shear flow properties of concentrated solutions of linear and star branched polystyrenes. Rheol Acta 1981;20:163-78. http://dx.doi.org/10.1007/BF01513059.

[42] Yu H, Huang N, Wang C, Tang Z. Modeling of poly(L-lactide) thermal degradation: theoretical prediction of molecular weight and polydispersity index. J Appl Polym Sci 2003;88:2557-62. http:// dx.doi.org/10.1002/app.12093. 